\title{
Estimular a inovação nas organizações
}

\author{
Anacleto Correia, Pedro B. Água \\ https://doi.org/10.37610/dyo.v0i75.612
}

Recibido: 11 de Febrero de 2021

Aceptado: 19 de Abril de 2021

\section{Resumo}

A inovação é fundamental para o crescimento das organizações, a melhoria dos processos e para a sustentabilidade organizacional. A falta de inovação organizacional pode ter efeitos nefastos de diversas formas, com oportunidades perdidas para tornar os processos mais eficientes. A inovação pode também reforçar a vantagem competitiva, permitindo a uma empresa dispor dum produto ou serviço de maior valor. O presente trabalho aborda a organização de forma holística e como entidade política, considerando as diversas áreas de governo organizacional. O trabalho fornece um quadro de referência do tema ‘organização para a inovação', que pode ser adaptado para acomodar realidades específicas.

\section{Palabras clave}

Política de Empresa, Inovação, Organização, Processo de Pensamento Lógico, Arquitetura de Inovação

\section{Introdução}

A inovação pode ser definida como a "melhoria de resultados com novos processos". Por seu lado, a arquitetura da inovação define-se, no âmbito deste trabalho, como um sistema, baseado em pessoas, que permite que outras pessoas inovem, por meio da alteração do ambiente em que trabalham (Miller \& Wedell-Wedellsborg, 2013). As organizações inovadoras possuem, regra geral, vantagens competitivas, com os benefícios associados, designadamente o crescimento da sua rendibilidade.

Como as organizações são sistemas - conjunto de elementos que operam em conjunto para um dado propósito (Forrester, 1968, p.1-1) - a abordagem adequada para lidar com as organizações é a abordagem de sistemas. Esta abordagem começa por questionar a principal razão para a mudança, interrogando, de seguida, o que mudar; mudar para o quê; e como causar (a desejada) mudança.

Para o efeito é apresentada uma metodologia que envolve várias fases, designadamente: (i) identificação de fatores críticos de sucesso para atingir o paradigma de inovação organizacional desejado; (ii) diagnóstico do atual paradigma de inovação organizacional; (iii) criação das transformações

\footnotetext{
Anacleto Correia * anacleto.correia@gmail.com

iD https://orcid.org/0000-0002-7248-4310 Pedro B. Água * pedroagua@gmail.com

iD https://orcid.org/0000-0003-1886-9938 * CINAV - Escola Naval, Almada, Portugal.
}

necessárias para preencher as lacunas, obtidas a partir da conceção da árvore da "realidade futura" - árvore lógica de causa-e-efeito, que mostra como ações selecionadas conduzirão a uma organização mais inovadora - e de duas árvores adicionais, uma destinada a identificar os obstáculos organizacionais à mudança e outra focada na execução da estratégia.

Este artigo foi desenvolvido em três partes que visam interligar três domínios, numa abordagem sistémica destinada a atingir o objetivo eleito. A primeira parte, "Uma abordagem holística às organizações - O Modelo de Política de Empresa", considera a abordagem de Valero \& Lucas (1991) como uma abordagem holística da organização como entidade política 'de facto' (Calleja \& Melé, 2017). Na segunda parte, "Rumo a uma organização mais inovadora", é relacionado o modelo de arquitetura para a inovação de Miller \& Wedell-Wedellsborg' com o Modelo de Política de Empresa num quadro conceptual holístico, proporcionando assim uma abordagem sistémica à criação de capacidades de inovação numa organização. Na terceira parte - Utilização do pensamento lógico no desenvolvimento duma estratégia de inovação - é apresentada uma forma pragmática de desenvolver uma estratégia de "reorganização para a inovação", baseada nas ideias de raciocínio lógico de Goldratt, detalhadas em Mabin \& Davies (2010).

\section{Uma abordagem holística às organizações - O Modelo de Política de Empresa (EPM)}

O trabalho dos dirigentes é escolher formas de agir de forma a alcançar uma situação futura da organização melhor 
do que a atual. Arquitetar e criar uma desejável nova cultura organizacional - uma cultura de inovação - obriga, em primeiro lugar, a abordar a organização de forma holística para garantir que consequências não intencionais e efeitos colaterais são minimizados. Entre as várias abordagens possíveis Christensen, Andrews \& Bower (1978) criaram as raízes iniciais do que pode ser considerado uma abordagem organizacional holística - Business Policy - constituído originalmente por três áreas de governo: (1) Estratégia Empresarial, (2) Realização da Estrutura e (3) Sistemas de Incentivo. Mais tarde, Valero \& Lucas (1991), desenvolveram o Modelo de Política de Empresa - um quadro conceptual de referência que evoluiu a partir dos trabalhos de política de empresa de Andrews (1971) e que concebe o trabalho da alta direção como incluindo quatro áreas principais de governo organizacional, juntamente com o desenvolvimento de procedimentos específicos que forneçam passos detalhados para a análise, seleção e implementação do futuro desejado para a organização. As quatro perspetivas ou áreas de governo são: (i) o Negócio; (ii) a Estrutura Diretiva; (iii) a Convivência Profissional (sistemas de incentivo); e (iv) a Configuração Institucional. Distinguir estes quatro aspetos é útil para preservar uma abordagem global (Calleja \& Melé, 2017).

Escolher o Negócio, ou estratégia corporativa, significa decidir realizar o conteúdo particular das atividades ou operações que, quando relacionadas, permitem a melhor evolução possível dos resultados da organização. O negócio é algo muito específico e pode referir-se a resultados de desempenho que não apenas o lucro. Reunir as pessoas e pôlas a trabalhar é um dos pilares básicos da direção. Por isso, criar uma estrutura diretiva significa confiar às pessoas partes particulares do que necessita de ser feito para efetivamente mover a organização rumo ao futuro e de forma equilibrada. Neste âmbito, a inovação não só depende da forma como as organizações estão estruturadas e gerem a informação, como da liberdade de escolha e tipo de autonomia permitida pelos valores e cultura da organização.
Através da Convivência Profissional a alta direção procura procedimentos que ajudem as pessoas a realizar o seu trabalho, isto é, garantir o compromisso profissional através de toda a organização. Fazer com que as pessoas que formam a organização trabalhem profissionalmente, sugerindo novas ideias através da criatividade e do conhecimento e promovendo a inovação, é uma das tarefas-chave dum dirigente. Estes critérios moldam a cultura da inovação organizacional e vice-versa. $\mathrm{O}$ desafio é garantir que o compromisso profissional de todas as pessoas na organização contribua positivamente para uma cultura de inovação.

Finalmente, a quarta área de governo organizacional é a Configuração Institucional, a qual é definida pelas dinâmicas da iniciativa, dinheiro e poder (Valero \& Lucas, 1991). A Configuração Institucional refere-se a aspetos determinantes da viabilidade da empresa como um todo. Neste sentido, o dinheiro dita o financiamento para iniciativas de inovação. O poder é um facilitador, ou às vezes um travão da inovação nas organizações, uma vez que pode promover ou restringir o nível de novas iniciativas organizacionais.

O Modelo de Política de Empresa de Valero e Lucas sugere que a gestão pode ser mais humanista, e prática na sua aplicação, sendo uma boa alternativa para a escola de pensamento tradicional que promove uma abordagem parcial da gestão estratégica, centrando-se quase exclusivamente nos lucros ou objetivos a curto prazo. Porque tem um âmbito abrangente, este modelo aborda a organização no seu todo, como um sistema. Este modelo tem a virtude de interligar uma visão humanista da direção de organizações. Por isso, estando os comportamentos inovadores e a criatividade relacionados com a motivação intrínseca, esta abordagem humanista é essencial para qualquer organização que tenha como objetivo a melhoria da sua cultura de inovação. A Tabela 1 resume o cruzamento da arquitetura de inovação com o Modelo de Política de Empresa acima mencionados.
Tabela 1 Inovação e as áreas de governo do Modelo de Política de Empresa

\begin{tabular}{|l|l|}
\hline \multicolumn{1}{|c|}{$\begin{array}{c}\text { Área de } \\
\text { Governo }\end{array}$} & \multicolumn{1}{c|}{ Relação da arquitetura de inovação com as áreas de governo } \\
\hline Negócio & $\begin{array}{l}\text { O negócio da organização consiste em oferecer serviços ou bens numa base } \\
\text { contínua obtendo uma certa rendibilidade; este conceito também é extensível } \\
\text { a organizações não lucrativas e organizações públicas. É, portanto, importante } \\
\text { especificar como a empresa garante a rentabilidade, e como isso se interliga } \\
\text { com a inovação em toda a organização. No caso de uma organização sem fins } \\
\text { lucrativos, esta também possui um modelo de negócio, baseado na eficiência, } \\
\text { novas e melhores formas de fazer as coisas com os recursos disponíveis. }\end{array}$ \\
\hline $\begin{array}{l}\text { Estrutura } \\
\text { Diretiva }\end{array}$ & $\begin{array}{l}\text { A estrutura de gestão da organização torna explícitos os responsáveis pela } \\
\text { execução das tarefas específicas. Assim, a organização para a inovação afetará } \\
\text { a estrutura e é afetada por ela também. }\end{array}$ \\
\hline $\begin{array}{l}\text { Convivência } \\
\text { Profissional }\end{array}$ & $\begin{array}{l}\text { Uma das tarefas-chave da gestão de topo é fazer com que as pessoas trabalhem } \\
\text { alinhadas com os objetivos organizacionais. Assim, devem ser pensados } \\
\text { "mecanismos de incentivo" adequados para garantir as motivações intrínsecas } \\
\text { e extrínsecas adequadas por forma a colocar e manter a organização no } \\
\text { caminho da inovação. }\end{array}$ \\
\hline $\begin{array}{l}\text { Configuração } \\
\text { Institucional }\end{array}$ & $\begin{array}{l}\text { Iniciativa, Dinheiro e Poder, são as três dimensões críticas da Configuração } \\
\text { Institucional de qualquer organização, e afetam (e são afetados) pela sua } \\
\text { relação sistémica na promoção duma estratégia organizacional de inovação. }\end{array}$ \\
\hline
\end{tabular}


A Configuração Institucional é de extrema importância para a sustentabilidade organizacional e onde as dimensões críticas de Iniciativa, Meios e Poder estão em jogo, por vezes acarretando dinâmicas complexas (Valero \& Figueroa, 2011). Tal sustentabilidade é ainda mais crítica sempre que uma organização se envolve numa estratégia de mudança, como seria o caso de mudar para uma nova cultura de inovação. Partindo dum sentido holístico, pode-se questionar: “- Como é que a reorganização para a inovação afetará as quatro áreas de governo organizacional? E vice-versa?”. Para responder a estas questões torna-se útil considerar a abordagem de Miller $\&$ Wedell-Wedellsborg (2013) no que concerne a arquiteturas de inovação.

\section{Rumo a uma organização mais inovadora}

Modelamos a realidade para decidir sobre as nossas ações. A utilidade de um modelo está muitas vezes em contrapeso com a sua complexidade e detalhe, o que nos faz procurar modelos mais simples, mas igualmente úteis. Alguns autores sugeriram que o uso de mais de um modelo fortalece a tomada de decisão, o que é uma questão central sempre que um processo de desenvolvimento estratégico é empreendido
(Page, 2018). Assim, o modelo aqui apresentado pode ser usado complementarmente com modelos mais quantitativos, sem perda de sentido.

Foi feito um esforço considerável para compreender como tornar uma organização mais inovadora. Neste sentido, Miller \& Wedell-Wedellsborg (2013) sugeriram um modelo assente em seis Fatores Críticos de Sucesso, considerados na estratégia de inovação e contexto de qualquer organização. Estes seis componentes são (no original): (1) Focus, (2) Connect, (3) Tweak, (4) Select, (5) Stealth storm + (6) persist.

Estes autores sugerem que geralmente as ideias, na sua forma original, raramente estão prontas para serem executadas ou implantadas numa organização precisando de sofrer ajustes (tweak) a fim de serem melhoradas. A Figura 1 ilustra como os seis fatores críticos de sucesso mencionados, CSF1-6, suportam o objetivo organizacional de mudar para um paradigma de maior inovação. Como sugerido por Miller \& Wedell-Wedellsborg $(2013 ; 2014)$ ter boas ideias é uma condição "necessária", no entanto "não é suficiente", ilustrando a Figura 1 uma possível rede de interdependências sistémicas entre os principais pilares da inovação, que carece de atenção se pretendemos elevar o nível de inovação na organização.
Figura 1 É relevante

entender como os fatores de inovação se interrelacionam entre si

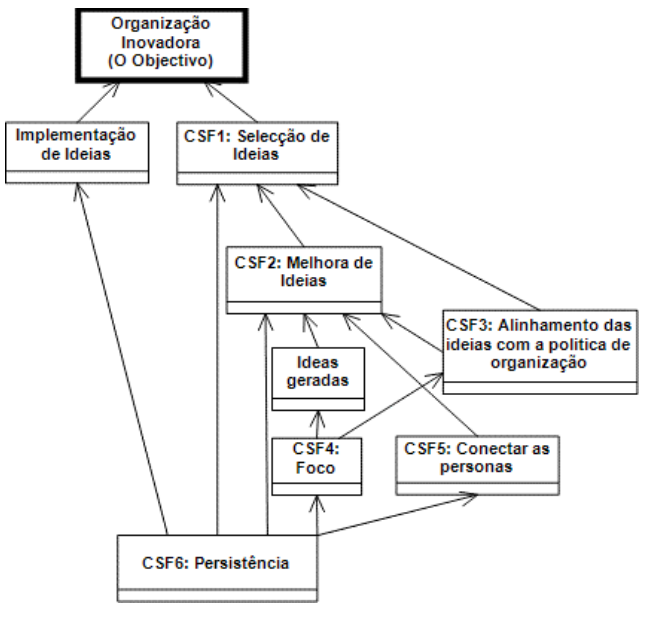

Reorganizar para a inovação requer uma "estratégia de mudança ", que por si só exige uma abordagem adequada e execução de uma estratégia com vista à normalização da inovação na cultura organizacional desejada. O termo "normalização" sugere que o processo de estratégia não termina com a execução da estratégia, devendo conduzir a uma nova "normal" de inovação (Vilà, 2011 \& 2012). Entre vários modelos possíveis, a Teoria das Restrições providencia uma abordagem lógica ao processo de conceção de uma tal estratégia, uma vez que permite estabelecer relações de causa e efeito, com o reconhecimento do problema estratégico e identificação das causas (raízes) dos problemas organizacionais que inibem a inovação.

\section{Utilização do pensamento lógico no desenvolvimento de uma estratégia de inovação}

Estruturas tradicionais, como as encontradas em certas organizações (e.g. erviços Públicos, Forças Armadas, ou grandes empresas com muitos anos de existência) são tipicamente mais resistentes à mudança. Este facto tem a sua explicação no processo de aprendizagem e memória organizacional, responsáveis pelo estabelecimento de muitos ciclos de realimentação negativos, ou de equilíbrio, decorrentes do processo de aprendizagem. Para ilustrar, considere-se o ciclo causal negativo na Figura 2a (a notação 
de diagramas causais é apresentada no Anexo A). Quando A aumenta B tende a aumentar, mas, tal dinâmica no aumento de B irá forçar A na direção oposta. Com o tempo, estabelecem-se nas organizações mais destes ciclos de equilíbrio (ou negativos) e, como consequência, assiste-se a maior resistência à mudança.

Assim, sempre que tentamos alterar o parâmetro A, mais ciclos de feedback negativos tentarão evitar que ele mude (Figura 2b). Tais ciclos de realimentação (controlo) trazem estabilidade aos sistemas (organizações), no entanto se é necessária uma mudança, estes ciclos de equilíbrio comportarse-ão como travões organizacionais face à mesma. Para a gestão da mudança há que ter critérios para aliviar alguns destes ciclos de realimentação negativos - o que se traduz na eliminação de algumas políticas organizacionais e no desenho e estabelecimento de novas. Exemplos de políticas organizacionais representativos destes ciclos negativos vão desde procedimentos específicos (potencialmente desatualizados), até restrições culturais, como o típico "não é assim que as coisas funcionam por aqui".
Figura 2 Resistência à mudança como resultado da ação de ciclos causais negativos

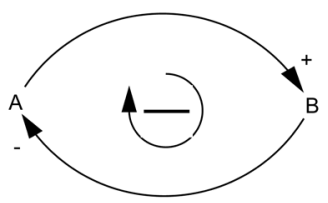

(a)

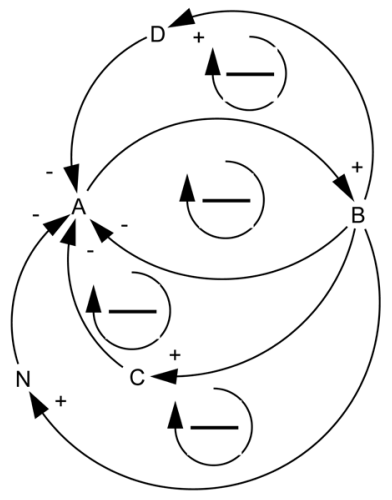

(b)
Se os ciclos de realimentação negativos são os "travões" das organizações, então os ciclos de realimentação positiva são os "aceleradores". Estes são estabelecidos igualmente mediante criação e/ou alteração de políticas organizacionais - tarefa da gestão de topo.

A inovação é um imperativo e a mudança é essencial. $\mathrm{O}$ Processo de Pensamento Lógico, inicialmente introduzido por Eliyahu Goldratt (Goldratt, 1994) na sua Teoria das Restrições sugere uma possível abordagem para a resolução de problemas, delimitada pelas seguintes quatro perguntas:

1. Por que mudar?

2. O que mudar?

3. Mudar para o quê?
4. Como provocar a mudança?

A resposta à primeira pergunta - Por que mudar? - é dada pelo imperativo da inovação. As três restantes questões são de seguida respondidas.

Tendo como pressuposto as dependências estabelecidas na Figura 1 e abordando a organização de forma holística com o modelo de política de empresa referido, a fase seguinte requer o desenho de uma "Árvore lógica da realidade presente", a fim de elicitar as causas dos problemas existentes no paradigma atual. Tal árvore desenvolve-se de baixo para cima, sendo algumas explicações devidas. Os acrónimos "UDE" representam efeitos indesejáveis (Undesirable Effects) desencadeados pelas cadeias precedentes de causa, os quais se pretendem eliminar. É de salientar que, na árvore, são as "causas" as raízes do problema e é nelas que será necessário atuar. 

da realidade corrente: representa o paradigma atual respeitante à capacidade de inovação da organização.
Figura 3 Árvore estratégica

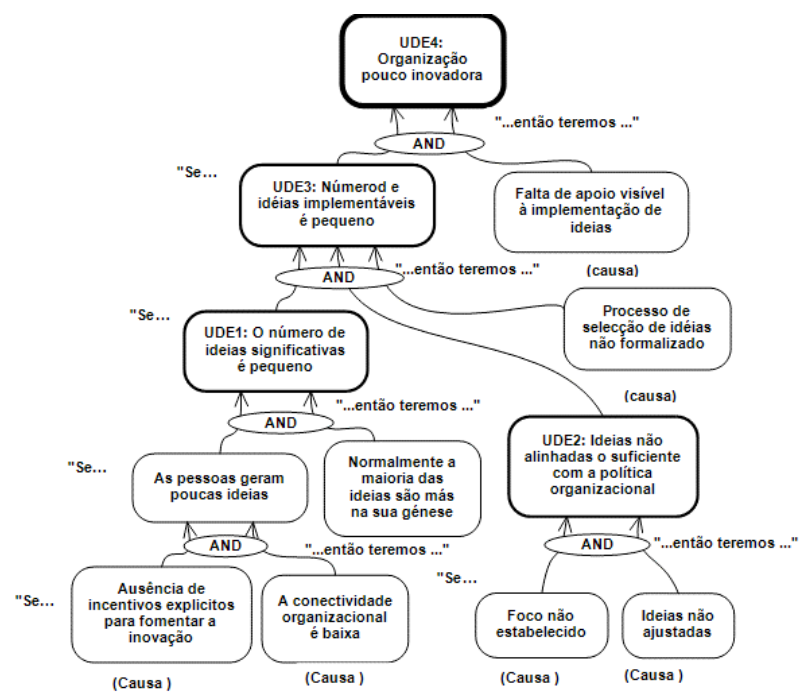

Concentrando seguidamente nas causas-raiz identificadas ("O que mudar?"), desenvolve-se o desenho de uma nova solução cruzando os fatores críticos de sucesso para a inovação com cada uma das quatro áreas de governo do modelo de politica de empresa, a fim de eliminar os efeitos indesejáveis e obter uma nova árvore lógica - a Árvore da Realidade Futura (Goldratt, 1994; Mabin \& Davies, 2010).
Esta fase exige que se abordem as causas profundas dos problemas, tendo em conta como a organização funciona, algo que carece de análise de políticas e dos processos organizacionais com equipas de gestores seniores, com compreensão holística da organização. A Tabela 2 resume as principais questões a serem colocadas para projetar a Árvore da Realidade Futura.
Tabela 2 Quadro conceptual do Modelo de Política de Empresa que apoia a organização de estratégias de inovação.

\begin{tabular}{|l|l|l|}
\hline $\begin{array}{l}\text { Área de } \\
\text { Governo }\end{array}$ & $\begin{array}{l}\text { Questões pertinentes no contexto da reorganização } \\
\text { para a inovação }\end{array}$ & Ações \\
\hline Negócio & $\begin{array}{l}\text { Quais são as condições necessárias para uma organização } \\
\text { mais inovadora? } \\
\text { Como aumentar o número de ideias na organização? } \\
\text { Como melhorar a qualidade das ideias geradas? } \\
\text { Como garantir o alinhamento entre ideias geradas e a } \\
\text { estratégia da organização? }\end{array}$ & $\begin{array}{l}\text { INJ 4 } \\
\text { INJ 5 } \\
\text { INJ 6 }\end{array}$ \\
\hline $\begin{array}{l}\text { Estrutura } \\
\text { Diretiva }\end{array}$ & $\begin{array}{l}\text { Como é que a estrutura de gestão da organização torna } \\
\text { explícitos os responsáveis pela realização das tarefas } \\
\text { concretas de organizar e promove a inovação como } \\
\text { capacidade organizacional? } \\
\text { Como inibe a inovação? }\end{array}$ & $\begin{array}{l}\text { INJ 1 } \\
\text { INJ 6 }\end{array}$ \\
\hline $\begin{array}{l}\text { Convivência } \\
\text { Profissional }\end{array}$ & $\begin{array}{l}\text { Como motivar as pessoas para que contribuam com ideias } \\
\text { inovadoras? } \\
\text { Como tornar as pessoas mais conscientes da necessidade } \\
\text { duma mudança de paradigma de inovação na organização? }\end{array}$ & $\begin{array}{l}\text { INJ 2 } \\
\text { INJ 3 }\end{array}$ \\
\hline $\begin{array}{l}\text { Configuração } \\
\text { Institucional }\end{array}$ & $\begin{array}{l}\text { Como institucionalizar a reorganização para a inovação na } \\
\text { cultura organizacional? }\end{array}$ & INJ 1 \\
\hline
\end{tabular}

A Figura 4 mostra a Árvore da Realidade Futura, com várias ações a injetar (INJ\#) para mudar a arquitetura de inovação e obter um melhor desempenho, aproximando assim a organização do seu objetivo - tornar-se numa organização mais inovadora. Na figura é visível o símbolo "MAG", que simboliza uma conjunção "AND" onde o efeito é potencialmente (ceteris paribus) ampliado pela ação conjunta de diversas influências que por ele passam. As "injeções" (INJ\#) identificadas neste modelo são as seguintes:
- $\quad$ INJ1 - Criar uma Unidade de Inovação Organizacional com um Diretor de Inovação (CIO - Chief Innovation Officer).

- INJ2 - Estabelecer um "Sistema de Incentivos à Inovação", para que as pessoas estejam cientes dos benefícios pessoais e organizacionais de contribuir para a inovação. 
Figura 4 Árvore da Realidade Futura: os retângulos representam ações a injetar

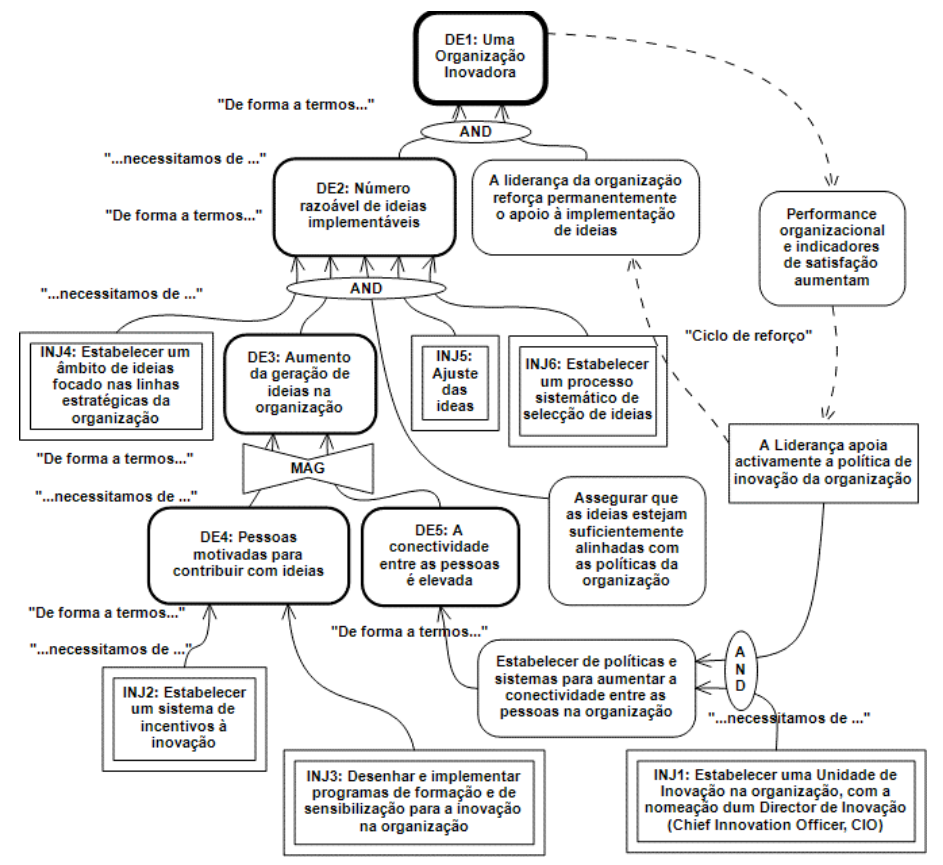

- INJ3 - Projetar e implantar programas de consciencialização e de formação em inovação, que devem ser realizados em toda organização, a fim de integrar as pessoas no quadro de mudança organizacional desejável. Isso apela à motivação intrínseca das pessoas, ao compreender que estarão a contribuir para uma melhor organização.

- $\quad$ INJ4 - Estabelecer o foco, para que as pessoas não gerem apenas ideias, mas ideias que estão alinhadas e apoiam a estratégia organizacional.

- $\quad$ INJ5 - Sistematizar, verificar e ajustar ideias em fases iniciais das mesmas, de modo a que o número de ideias relevantes (ceteris paribus) aumente.

- INJ6 - Estabelecer um "sistema de seleção de ideias", para que a organização garanta que as ideias de menor potencial sejam descartadas mais cedo, minimizando assim o desperdício de recursos. Este é um passo delicado, pois as pessoas podem sentirse desmotivadas e deixar de contribuir com novas ideias, caso as suas propostas sejam sistematicamente eliminadas.

Com os efeitos desejados agora visíveis (DE1 a DE5), a Árvore da Realidade Futura desejada responde à terceira questão (Mudar para o quê?).

Pode-se agora passar à última questão - Como causar a mudança? -, ou como implantar a estratégia formulada para reorganizar para a inovação. A resposta a esta questão é abordada mediante uma nova categoria de árvores lógicas - as árvores de pré-requisitos -, árvores que são construídas por forma a garantir que as ações a injetar encontram as "condições necessárias" para que possam ser implementadas na prática. Tal acarreta eliminação de obstáculos de diversa natureza - desde recursos até políticas organizacionais e procedimentos. A Figura 5 ilustra as seis ações de injeção identificadas.

As Árvores de Pré-requisitos e as devidas interligações com a Árvore da Realidade Futura são o ponto de partida para a fase final de execução da estratégia de reorganização para a inovação (Como causar a mudança?). Os hexágonos sinalizam obstáculos que devem ser removidos a fim de implementar as ações desejadas.

Vários autores assinalaram a importância de não subestimar a resistência à mudança na execução de transformações organizacionais (Kotter, 1996; Sull, D., Homkes, R., Sull, C., 2015). Os Pré-requisitos abordam esses obstáculos potenciais à reorganização para a inovação. Finalmente, a fim de implementar tal estratégia, os processos de pensamento lógico incluem um sexto tipo de árvore - a árvore de transição (TT, Transition Tree) - que estabelece pontes para o mundo da gestão de projetos, fornecendo redes de atividade, e permitindo a calendarização destinada à execução.

Partindo das árvores de pré-requisitos anteriores pode-se projetar um mapa de atividades - a "árvore de transição" - para apoiar a implementação de toda uma estratégia destinada a transformar a organização. Tal árvore de transição terá como referências as ações a injetar, ilustradas nas árvores de prérequisitos (Figura 6). 
Figura 5 Árvore de

Pré-requisitos: antecipa e supera obstáculos às ações pretendidas
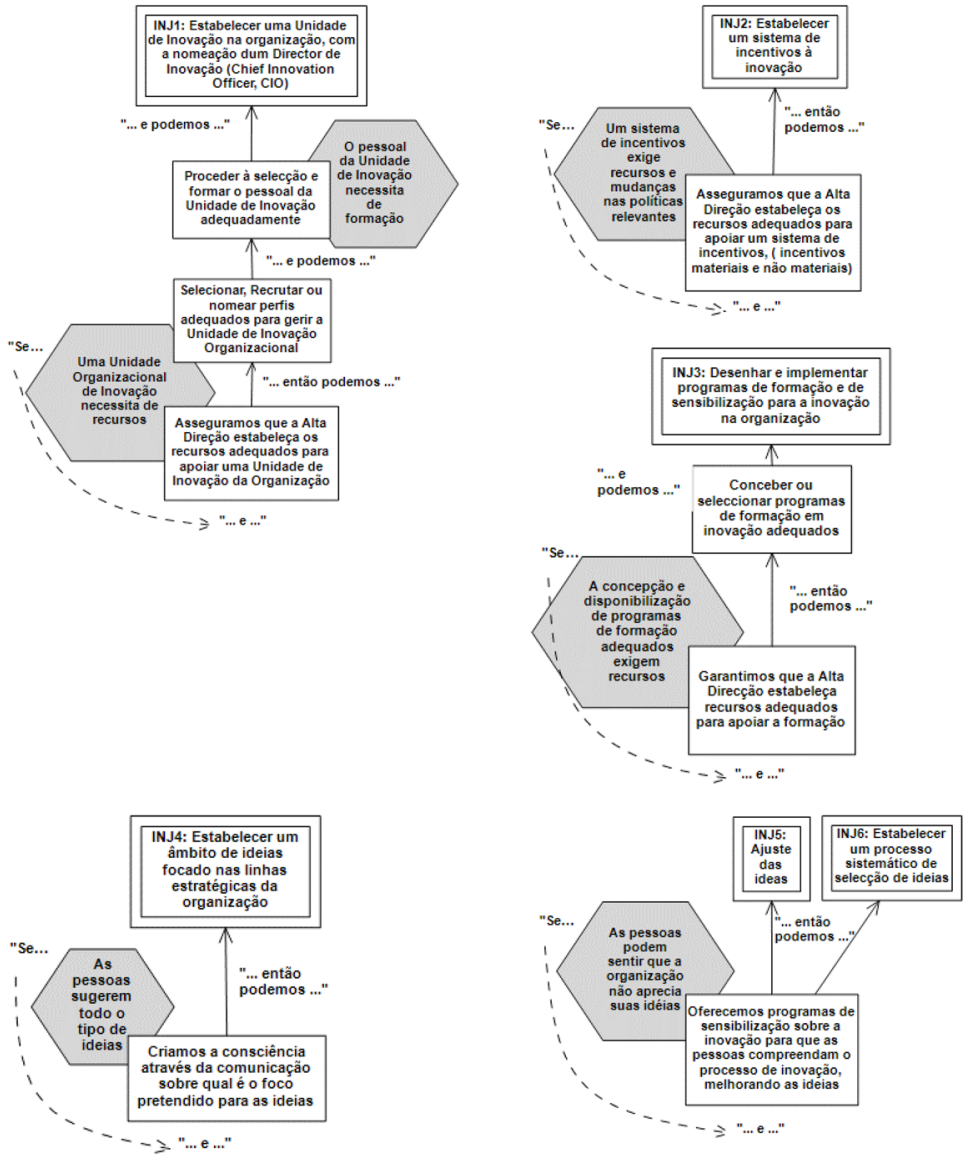

Escusado dizer que a solução desenvolvida para o problema estratégico - como tornar uma organização mais inovadora beneficiaria com a verificação da mesma através das variáveis DOTMLPFI (Doctrine, Organization, Training, Materiel,
Leadership, Personnel, Facilities \& Interoperability), a fim de clarificar a existência de potenciais condicionalismos. Decorrente desse confronto pode-se aperfeiçoar a solução de forma a ficar mais robusta.
Figura 6 Árvore de transição: o comprimento das barras representa a duração das tarefas

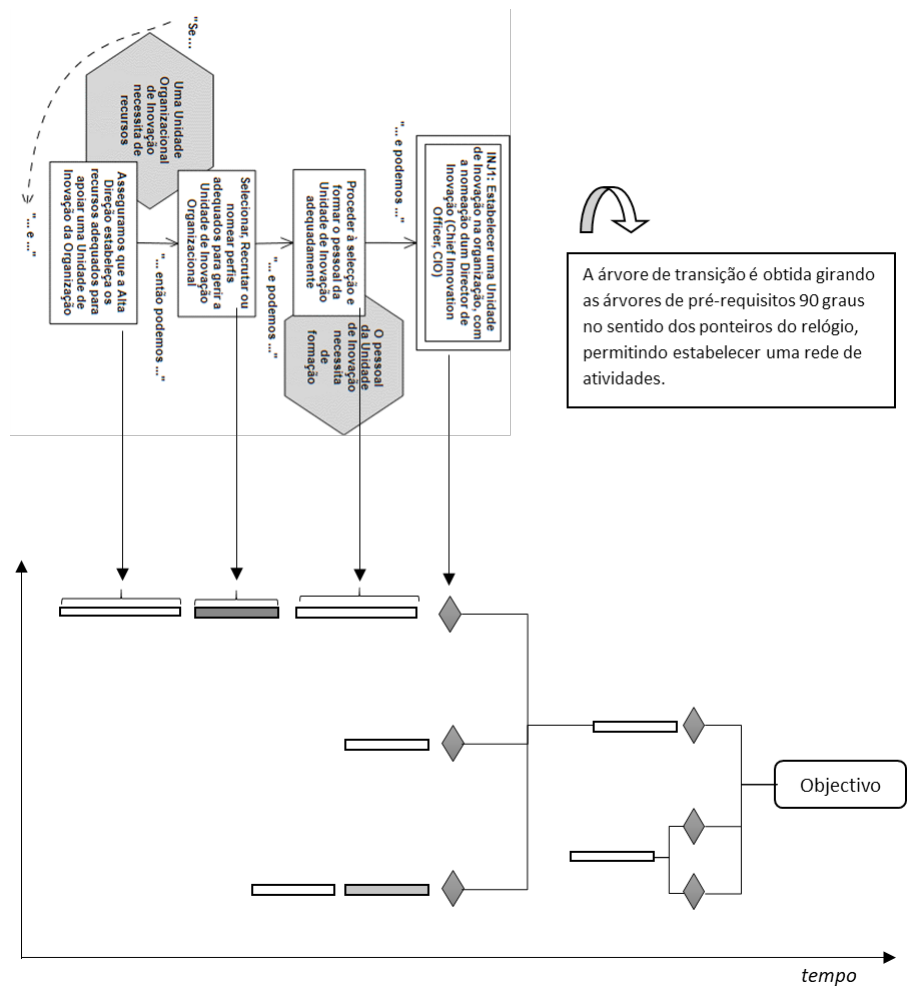




\section{Discussão / Conclusão}

Este artigo apresenta uma abordagem à arquitetura de inovação organizacional fazendo uso de diversos modelos: $\mathrm{O}$ Modelo de Política de Empresa; Arquitetura de Inovação; e os Processos de Pensamento Lógico de Goldratt. É um modelo suficientemente abrangente para uma primeira abordagem à estratégia da organização para a inovação, podendo ser detalhado para cada organização específica.

A partir da abordagem elaborada, existem várias medidas tangíveis que, ceteris paribus, permitirão melhorar o desempenho organizacional no que respeita à capacidade de inovação. Essas medidas devem garantir que a organização progrida numa Curva de Maturidade da Inovação, desde as fases iniciais até atingir uma cultura organizacional inovadora perpétua. O modelo é suficientemente útil para fornecer orientação estratégica, identificando várias áreas-chave onde concentrar a atenção, bem como as seguintes medidas: (i) na primeira fase, sugere-se a necessidade de conceber um programa ou seminário de inovação de curta duração e de o realizar nas mais variadas unidades organizacionais, a fim de criar um nível adequado de consciência sobre a importância, possibilidades e mecanismos de inovação; (ii) na segunda fase, para progredir de um patamar de consciência de inovação organizacional para um nível mais elevado de maturidade em termos de cultura de inovação organizacional, pode optarse por selecionar grupos de pessoas (Innovation Champions) para frequentar seminários avançados sobre o assunto - de preferência "feitos à medida" e na organização; (iii) na terceira fase estarão estabelecidas as condições necessárias para a criação de uma sólida "Unidade de Inovação Organizacional”, liderada por um alto dirigente com reporte direto à gestão de topo; (iv) na quarta fase vários programas podem ser lançados, como seria o caso duma "plataforma de seleção de ideias" e "comités de inovação" liderados por Innovation Champions; (v) finalmente, na quinta fase, pode ser critico criar um "sistema de incentivos à inovação", a fim de tornar a inovação sistemática, uma vez que a motivação é sempre um fator para obter o melhor das pessoas. Este sistema de incentivos pode beneficiar da criação de "prémios de inovação", tornando a inovação um critério de avaliação para promoção.

Às vezes a busca pela melhor solução é ineficiente, e os dirigentes, gestores e executivos precisam de soluções práticas, onde se procura o compromisso entre a perfeição e pragmatismo. Sendo modelos, todos são representações imperfeitas da realidade percebida. Como sugerido por Greenberg, Crenson e Crissey (1976, p. 70-71): "Nenhum modelo pode ser completamente validado ...,", útil", "inspirador", ou "convincente", são adjetivos mais apropriados para modelos do que "válido". Na mesma linha, (Sterman, 2000, p.890): Todos os modelos estão errados, de forma que nenhum modelo é válido ou verificável no sentido de estabelecer a" verdade". A pergunta que devemos colocar nunca é se um modelo é perfeito, mas se é útil.
Nenhum modelo é perfeito, no entanto, a utilidade é um critério razoável, onde a simplicidade está normalmente em desacordo com a complexidade. Melhor do que decidir que modelo escolher entre várias alternativas, pode ser mais prudente usar vários modelos simultaneamente que se complementem (Page, 2018). Por vezes, usando uma abordagem qualitativa como a apresentada neste artigo, fornecer uma boa visão e o ponto de partida para o uso de modelos mais elaborados e complexos.

\section{Referências}

Andrews, K. R. (1971). The Concept of Corporate Strategy. 3rd Edition, Dow Jones Irwin, Berkeley California.

Calleja, R., Melé, D. (2017). Valero's "Enterprise Politics": A model of humanistic management and corporate governance. Journal of Management Development, 36(5), 644-659.

Christensen, C. R., Andrews, K.R., \& Bower, J. L. (1978). Business Policy: Text and Cases. $4^{\mathrm{a}}$ Ed. Homewood: Illinois. R. D. Irwin Ed.

Forrester, J. W. (1961). Industrial Dynamics. Massachusetts: Pegasus communications, USA.

Forrester, J. W. (1968). Principles of Systems. Massachusetts: Pegasus communications, USA.

Goldratt, E. (1994). It's Not Luck. Gower Publishing Limited. Hampshire, England.

Kotter, J, P. (1996). Leading Change. Harvard Business School Press. Boston, MA: USA.

Mabin, V, J., Davies, J. (2010). 'The TOC Thinking Processes', in Cox, J.F., Schleier, J. G. (editors). (2010). The Theory of Constraints Handbook. McGraw-Hill Ed. USA.

Miller, P., Wedell-Wedellsborg, T. (2013). Clearing the Path to Innovation. IESE Insight. First Quarter 2013, Issue 16.

Miller, P., Wedell-Wedellsborg, T. (2014). Get More Actionable Ideas from Your Employees. Harvard Business Review. November.

Page, S. E. (2018). Why "Many-Model Thinkers" Make Better Decisions. Harvard Business Review. November.

Sterman, J. (2000). Business dynamics: Systems thinking and modeling for a complex world. New York: Irwin McGraw-Hill. 
Sull, D., Homkes, R., Sull, C. (2015). "Why Strategy Execution Unravels - and What to Do About It". Harvard Business Review, March 2015 issue.

Valero, A., \& Lucas, J. L. (1991). Política de empresa: El gobierno de la empresa de negocios. Pamplona: Eunsa. (Spanish)

Valero, A., \& Figueroa, E. T. (2011). La empresa de negócios y la alta dirección: Procedimientos politicos de gobierno (3a Ed.). Pamplona: Eunsa. (Spanish)

\section{Anexo A: Diagramas Causais}

Um Diagrama Causal é um modelo das relações importantes entre variáveis ou parâmetros dum sistema. É uma ferramenta usada no pensamento sistémico que tem algumas virtudes, a saber:

- É uma forma simples de representar ideias, que às vezes são confusas nas fases iniciais de qualquer estudo dum sistema.

- $\quad$ Permite uma comunicação clara e eficaz com as partes interessadas sobre um modelo ou estudo.
Vilà, J. (2011). Innovative Culture: Values, Principles and Practices of Senior Executives in Highly Innovative Companies. Teaching Note SMN-681-E. IESE Publishing.

Vilà, J. (2012). Normalize Innovation to Transform Your Firm. IESE Insight. Third Quarter 2012, Issue 14.
Figura A1 As setas marcadas combinam-se em Diagramas Causais
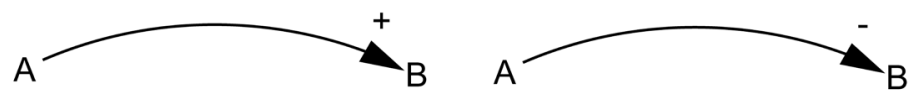

Combinações destes dois tipos de relações permitem desenhar diagramas causais tão complexos quanto se queira. Particularmente importantes são os ciclos de feedback que
Uma relação causal usa sinais "+" e "-" para indicar o tipo (ou direção) de influência entre duas variáveis. Por exemplo, uma relação causal entre duas variáveis A e B com um sinal "+" significa que elas variam na mesma direção (efeito direto.) Ou seja, sendo tudo o resto igual, quando A aumenta, B tende a aumentar ou quando A diminui, B tende a diminuir. Da mesma forma, uma relação com um sinal "-" significa uma variação na direção oposta (efeito inverso). Ou seja, sendo tudo o resto igual, quando A aumenta, B tende a diminuir e quando A diminui, B tende a aumentar:

Figura A2 Os sinais “+” e

“_ "indicam a polaridade do

ciclo causal

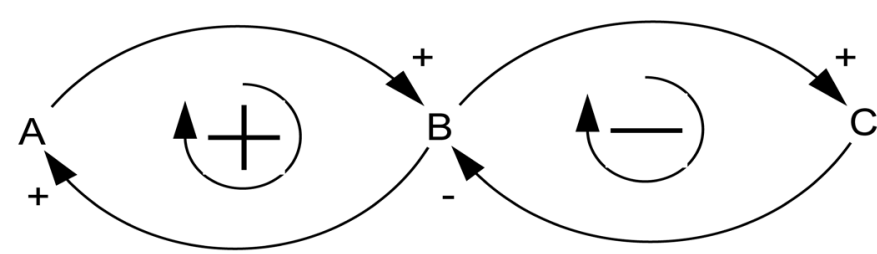

É normal representar o efeito de A sobre B. No entanto, esta representação é incompleta, porque o resultado de B é uma nova condição no sistema que por sua vez pode influenciar A. Num ciclo positivo (ciclo do reforço) não há influências negativas ou existe um número par de relações causais com um sinal "-". Num ciclo negativo (ciclo de equilíbrio) há um número ímpar de relações causais com um sinal "-". Por si só, um diagrama causal não mostra a dinâmica que podem surgir na estrutura de um sistema, e que potencialmente podem ser positivos ou negativos, como ilustrado na Figura A2. 